\title{
Evidence that $(+)$-endo-Brevicomin is a Male-Produced Component of the Southern Pine Beetle Aggregation Pheromone
}

\author{
Brian T. Sullivan • William P. Shepherd • \\ Deepa S. Pureswaran - Takuya Tashiro $\cdot$ Kenji Mori
}

Received: 1 March 2007 /Revised: 12 June 2007 /Accepted: 18 June $2007 /$

Published online: 13 July 2007

(C) Springer Science + Business Media, LLC 2007

\begin{abstract}
Previous research indicated that the aggregation pheromone of the southern pine beetle, Dendroctonus frontalis, is produced only by females, the sex that initiates attacks. We provide evidence indicating that secondarily arriving males augment mass aggregation by releasing the attractive synergist $(+)$-endo-brevicomin. Healthy pines artificially infested with both sexes of $D$. frontalis were significantly more attractive to conspecifics than trees infested solely with females. Coupled gas chromatography-electroantennographic detection (GC-EAD) analyses of volatiles isolated from male beetles revealed substantially greater olfactory sensitivity by $D$. frontalis to endo-brevicomin than to any other component. The threshold of detection of both sexes for $(+)$-endo-brevicomin was four orders of magnitude lower than for its antipode and at least one order of magnitude lower than for either enantiomer of frontalin, the major female-produced aggregation pheromone component. Pairing with a female in a gallery stimulated individual male beetles to produce hundreds of nanograms of $(+)$-endo-brevicomin. $(+)$-endo-Brevicomin was detected in a small percentage of female $D$. frontalis, whereas (-)-endo-brevicomin was never detected in either sex. In field trapping bioassays, we confirmed that $(+)$-endo-brevicomin is a potent synergist for attractive combinations of frontalin and pine turpentine. However, $(+)$-endobrevicomin failed to attract $D$. frontalis either when presented alone or in combination with turpentine. We postulate that mass colonization of host trees by $D$. frontalis is mediated by distinct semiochemicals from both sexes rather than females alone. Our discovery of a key aggregation pheromone component in such an apparently well-studied species implies that
\end{abstract}

B. T. Sullivan $(\varangle) \cdot$ W. P. Shepherd

USDA Forest Service, Southern Research Station, 2500 Shreveport Hwy, Pineville, LA 71360, USA

e-mail: briansullivan@fs.fed.us

D. S. Pureswaran

Department of Entomology, Michigan State University, E. Lansing, MI 48824-1115, USA

T. Tashiro

RIKEN Research Center for Allergies and Immunology, Hirosawa 2-1, Wako, Saitama 351-0198, Japan

K. Mori

The University of Tokyo, Bunkyo-ku, Tokyo 113-0023, Japan

Springer 
the pheromone models of other bark beetles could benefit from systematic reexamination using newer technologies. Additionally, baits fortified with $(+)$-endo-brevicomin may enhance pest management strategies that exploit attractants for $D$. frontalis.

Keywords Attractant - Synergist - Bark beetle - GC-EAD - Scolytinae - Semiochemical . Sexual dimorphism $\cdot$ Aggregation pheromone $\cdot$ Coleoptera

\section{Introduction}

The pheromone system of the southern pine beetle, Dendroctonus frontalis, Zimmermann (Coleoptera: Curculionidae: Scolytinae), an aggressive tree-killer of Pinus spp. in southern North America and Central America, has been studied since the mid-1960s (reviewed in Smith et al. 1993). According to the model proposed by Renwick and Vité (1969) and subsequently refined (Vité and Francke 1976; Payne 1980; Smith et al. 1993), female beetles (the "pioneer" sex) initiate colonization of new host trees by boring into the bark while releasing the aggregation pheromone components frontalin and trans-verbenol. Frontalin is considered the major component of the aggregation pheromone, based both upon its ability to attract conspecifics in the absence of other compounds and the failure of any compound or combination to attract $D$. frontalis in its absence (Smith et al. 1993; Skillen et al. 1997). A blend of frontalin, trans-verbenol, and alpha-pinene (released by the host) attracts both sexes: males that pair with established females and females that initiate their own entrances in the bark. Attraction of sufficient numbers of conspecifics results in a lethal "mass attack" in which the host's constitutive resin defenses become so compromised that beetles can feed and reproduce unimpeded in the phloem. Arriving males produce verbenone and endo-brevicomin, compounds thought to interrupt attraction to the aggregation pheromone once the host is fully colonized and cause termination of mass attack.

Evidence that male-produced endo-brevicomin and verbenone function as antiaggregation pheromones includes: (1) production solely or predominantly by the second-arriving sex (Pitman et al. 1969; Hughes 1973), (2) the ability to inhibit attraction of $D$. frontalis to traps baited with frontalin plus trans-verbenol and/or host-compounds (Renwick and Vité 1970; Vité and Renwick 1971; Payne et al. 1978; Salom et al. 1992), and (3) the ability of devices releasing these compounds to reduce the numbers of beetles landing on hosts (Payne et al. 1977; Payne and Richerson 1979) or stop the expansion of individual $D$. frontalis infestations (Payne et al. 1992). However, Billings (1985) reported that low release rates of endo-brevicomin and verbenone enhanced attraction of flying $D$. frontalis. Subsequently, Vité et al. (1985) demonstrated that pure $(+)$-endo-brevicomin increased catches of $D$. frontalis in traps baited with frontalin and turpentine, whereas the (-) enantiomer had an antagonistic effect.

The true function of endo-brevicomin in the biology of $D$. frontalis has remained unclear for at least two reasons. First, conflicting evidence exists regarding the enantiomeric composition of endo-brevicomin (Redlich et al. 1987; Grosman et al. 1997), hence the relative amounts of the apparently repellant $(-)$ and the attractive $(+)$-enantiomers produced by $D$. frontalis is uncertain. Second, addition of male $D$. frontalis to female-infested pine bolts failed to alter responses of conspecifics (Coster et al. 1977; Svihra 1982), suggesting that male-produced semiochemicals neither inhibit nor enhance aggregation during host colonization.

In this paper, we reexamine the role of male beetles in semiochemical-mediated host colonization by $D$. frontalis. We assayed whether male beetles could alter attraction of conspecifics to female attacks when living pines were used as the host substrate rather than

$$
\text { Springer }
$$


pine bolts as in earlier studies. We then performed electroantennogram studies with volatiles derived from both newly emerged and mining $D$. frontalis to identify potential male-produced aggregation pheromone components, and we compared olfactory sensitivity for $(+)$-endo-brevicomin, a candidate male-produced aggregation pheromone component, against its antipode and the enantiomers of frontalin. We examined the influence of both feeding and pairing on the quantity and enantiomeric composition of endo-brevicomin produced by male $D$. frontalis and performed field trapping bioassays to determine the behavioral activity of $(+)$-endo-brevicomin and elucidate its likely function in host colonization.

\section{Materials and Methods}

Experimental Insects Adult $D$. frontalis were collected in a rearing box fitted with a refrigerated insect trap (Browne 1972) as they emerged from bark or bolts taken from naturally infested trees cut in the National Forests of Mississippi and Alabama in 20022006. Beetles were held for up to 1 week at $4^{\circ} \mathrm{C}$ in plastic Petri plates lined with pieces of moistened Kimwipe ${ }^{\circledR}$ (Kimberly-Clark, Roswell, GA, USA). Beetles were sexed by the mycangial bulge on the female pronotum and the deep median groove on the male frons (Wood 1982). Only undamaged beetles were used in experiments.

Attraction of D. frontalis to Artificially Infested Trees Within a mixed pine/hardwood stand that had a suboutbreak population of $D$. frontalis (Homochitto National Forest, Mississippi, $31.5^{\circ} \mathrm{N}, 91.2^{\circ} \mathrm{W}$ ), we selected pairs of adjacent, apparently healthy loblolly pines, Pinus taeda $\mathrm{L}$. Trees in each pair were $15-40 \mathrm{~cm} \mathrm{DBH}$ (diameter breast height), located $>100 \mathrm{~m}$ from any other pair, and $>100 \mathrm{~m}$ from the nearest $D$. frontalis-infested tree. A saran screen cage ( $32 \mathrm{mesh}, 1.0 \mathrm{~m}$ tall) was wrapped around the trunk of each tree at a height of 1-1.5 m. Access to the cage interior was through a Velcro ${ }^{\circledR}$ closure that ran the length of the cage; the top and bottom of the cage were sealed tightly to the bark with a 10 -cm-wide strip of duct tape. To preclude beetle entry or escape through bark fissures, the outer bark was smoothed with a draw-knife where the top and bottom of the cage were taped to the tree. To prevent attacks by wild beetles, all noncaged portions from the soil to base of the crown were wrapped with clear polyethylene sheeting (6-ml thickness) secured with duct tape. Pines closer than $10 \mathrm{~m}$ to the caged trees were either removed or had their boles wrapped in sheeting to prevent "spillover" attacks. To promote successful attack of the trees by caged beetles, the primary resin defenses of each tree were challenged by stripping a 10 -cm-wide girdle of bark immediately below the cages during the day before and again on the day of introduction of female beetles to the cages.

On one tree of each pair, $100 \mathrm{D}$. frontalis females were sealed into the cage, and then, three nonbaited, 12-unit multiple funnel traps (Chemtica International, San Jose, Costa Rica) were suspended against the outside of the cage equidistant around the tree circumference. On the following day, trap catch was collected, and then, either 100 males or no further beetles were added to the cage, as determined by a coin toss. Beetles were collected again 2 and 4 days later. Peak attraction to naturally infested trees and artificially infested logs occurs 2-3 days after initiation of attacks (Coster and Vité 1965; Coster et al. 1977). After the final trap collection, infested trees were immediately felled, and the caged portions were removed for dissection in the laboratory. Approximately 1 week after felling of the first tree of each pair, the entire procedure was repeated on the second tree except that it received the opposite treatment with regard to the introduction of males. In total, eight 
pairs of trees were assayed between 20 June and 1 August 2006. We used paired $t$ tests to identify treatment effects on trap catch and numbers of attacks on trees. The proportions of males trapped per tree were normalized with $\arcsin { } x$, and treatments were compared with Student's $t$ test. Bonferroni's adjustment $(\alpha=0.017)$ was applied to comparisons of catch within the three trapping intervals.

Electrophysiological Analyses We examined relative olfactory sensitivities of $D$. frontalis to volatile compounds isolated from males. We quantitatively analyzed coupled gas chromatography-electroantennographic detection (GC-EAD) responses of beetles to 11 male-produced compounds that were shown in a previous, qualitative study to have olfactory activity (Sullivan 2005). In that study, single antennae from male and female $D$. frontalis were exposed to 0.1 beetle equivalents of the mid/hindgut extract of 100 newly emerged male $D$. frontalis. We also performed new GC-EAD analyses on the antennae of ten male and ten female $D$. frontalis exposed to volatiles from male beetles that had been paired with a female in a pine bolt $<1$ day (extraction treatment 3 , below). The pooled pentane extract from 15 males was concentrated until approximately $1 \mu$ l equaled 0.2 beetle equivalents, and this quantity was injected into the $\mathrm{GC}$, thus delivering 0.1 beetle equivalents to the antennal preparation (the effluent was split 1:1 between the GC's flame ionization detector [FID] and the antennal preparation). Otherwise, the GC-EAD apparatus and procedures were identical to those published by Sullivan (2005). For both GC-EAD data sets, raw response voltages for all compounds that produced an EAD deflection with at least four antennae were $\log$ transformed and then analyzed by repeated-measures analysis of variance (ANOVA) and Tukey's pairwise tests ( $\alpha=0.05$; SPSS 1997).

Because endo-brevicomin consistently produced greater antennogram responses than any other male-derived volatile, we generated dose-response curves to compare the relative olfactory sensitivity of $D$. frontalis to the separated enantiomers of both endo-brevicomin and the female-produced aggregation pheromone component frontalin. Antennae were exposed to mixtures containing tenfold dilutions of frontalin and endo-brevicomin (approximately $1000,100,10,1,0.1,0.01$, and $0.001 \mathrm{ng} / \mu \mathrm{l}$ of each enantiomer delivered to the antennae) as well as the EAD-active internal standard ( -$)$-verbenone at a fixed concentration (100 ng). Each experimental replicate consisted of a single GC-EAD run with a fresh antennal preparation and one of the dilutions assayed in random order. Enantiomers were separated on a GammaDex-225 column $(30 \mathrm{~m} \times 0.25 \mathrm{~mm} \times 0.25 \mu \mathrm{m}$ film; Supelco, Bellefonte, PA, USA) by using the temperature program $5 \%$ min from 60 to $117^{\circ}$, then $45^{\circ}$, $\min$ to $225^{\circ}$ held $5 \mathrm{~min}$. This program produced a $0.18-$ to $0.28-\mathrm{min}$ separation between the GC peaks of both the frontalin and endo-brevicomin enantiomers and a $>3.0$-min separation between peaks of the three compounds (Fig. 1). We were unable to identify a chiral column phase that reversed the elution order of the enantiomers of frontalin and endo-brevicomin, hence all GC-EAD runs were performed with $(+)$-frontalin and $(-)$-endo-brevicomin eluting ahead of their respective antipodes. To ensure that recent exposure to the antipode was not reducing antennal responses to the second-eluting enantiomer, GC-EAD runs were performed both with synthetically purified, single enantiomers (Phero Tech Inc., Delta, BC, Canada; $94-97 \%$ enantiomeric purity; two to four replicates per dilution) as well as racemic mixtures (four replicates per dilution) of frontalin and endo-brevicomin. Mean response voltages did not differ significantly between these data sets at any concentration (nonparametric $t$ test, $\alpha=0.05$, Microsoft ${ }^{\circledR}$ EXCEL 2002); therefore, the data were pooled. To minimize variation as a result of inconsistent quality of the antennal preparations, response voltages to frontalin and endo-brevicomin enantiomers were computed relative to response voltage to the internal standard, $(-)$-verbenone. The threshold of detection for each 


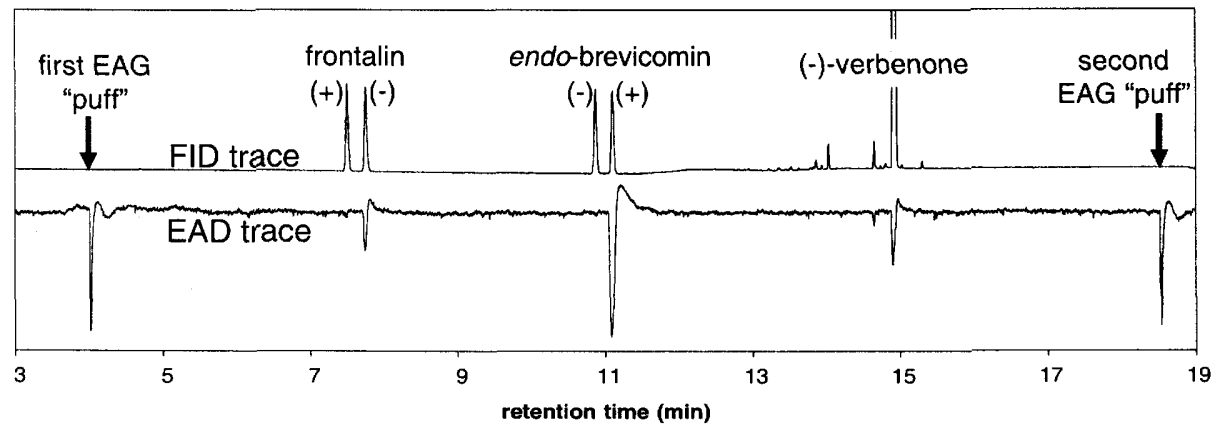

Fig. 1 GC-EAD trace from a male $D$. frontalis antenna exposed to one of the doses (10 ng) used to calculate dose-response curves for $D$. frontalis sensitivity to the enantiomers of frontalin and endo-brevicomin. The upper trace is from the GC's flame ionization detector $(F I D)$, while the lower trace is from the electroantennographic detector $(E A D)$. Enantiomers were separated on a gamma-cyclodextrin-phase capillary GC column. Verbenone was included in each injected dilution as an electrophysiologically active internal standard, and an electroantennogram $(E A G)$ stimulus (consisting of a blend of $D$. frontalis semiochemicals in a pasteur pipette) was "puffed" over the antenna at the beginning and at the end of each GC-EAD run to estimate decline in overall responsiveness of the antennal preparation during this interval

enantiomer was calculated as the lowest concentration for which the EAD deflection voltage exceeded the 90th percentile of the height of background noise on at least three out of eight runs $(P<0.038$, table of cumulative binomial probabilities; Bhattacharyya and Johnson 1977). Mean and standard error of responses to enantiomers were calculated for concentrations that exceeded the threshold of detection. To calculate the actual concentration of each enantiomer exposed to the antenna, the integration area of each FID peak during $0.2 \mathrm{~s}$ at maximum peak height was divided by the total integration area, multiplied by the known total quantity of enantiomer eluting, and then divided by the volume of air transferring the effluent to the antenna every $0.2 \mathrm{~s}$ (i.e., $1.33 \mathrm{ml}$ ).

For all GC-EAD data sets, the heights of signal voltage deflections in each GC-EAD run were corrected for the inevitable loss of responsiveness in the antennae that occurred over the duration of the run. This correction was accomplished by measuring the decline in electroantennogram (EAG) response to a uniform stimulus (a mixture of $D$. frontalis semiochemicals delivered from a Pasteur pipette) "puffed" over the antenna at the beginning and end of each GC-EAD run (Fig. 1). The percent reduction in height of the response to the second EAG stimulus relative to the first was assumed to be a linear function of time and to affect all stimulants equally.

Pheromone Isolation and Analysis We used procedures described by Sullivan (2005) and determined the influence of feeding and pairing on the quantities of endo-brevicomin, frontalin, verbenone, and myrtenol produced by one or both sexes of $D$. frontalis. We sampled volatiles from individual beetles that either (1) were newly emerged (i.e., had appeared in the rearing box during the previous 3 days), (2) had been mining singly in a freshly cut loblolly pine bolt for $<1$ day, or (3) had been mining in a bolt with a mate for $<1$ day (females had initiated galleries 1 day before the introduction of males). To obtain attacks on bolts, we confined beetles within gelatin capsule halves secured over 1-mmdiameter holes drilled into the bark. Beetles that produced frass in treatments 2 and 3 were carefully dissected from the bark and kept up to $4 \mathrm{~h}$ at $0-4^{\circ} \mathrm{C}$ before headspace sampling. To collect volatiles from beetles, they were held singly for $16-20 \mathrm{~h}$ at room temperature in static headspace sampling enclosures (Sullivan 2005) containing $\sim 3 \mathrm{mg}$ of Super Q 
adsorbent (Alltech, Deerfield, IL, USA). Afterward, the Super Q and the excised mid/ hindgut of each beetle were extracted together in a total of $100 \mu$ pentane spiked with $180 \mathrm{ng}$ of the internal standard heptyl acetate. In one experiment, 31-34 individuals per treatment per sex were sampled from a single pool of beetles derived from infestations in the Chickasawhay National Forest of southeastern Mississippi $\left(31.5^{\circ} \mathrm{N}, 89.0^{\circ} \mathrm{W}\right)$. In addition, we checked for possible regional variation in the enantiomeric ratios of endobrevicomin by sampling additional males in treatment 3 above from both the Homochitto National Forest in western Mississippi $\left(31.4^{\circ} \mathrm{N}, 91.1^{\circ} \mathrm{W} ; N=4\right)$ and the Talladega National Forest of Alabama $\left(32.9^{\circ} \mathrm{N}, 87.1^{\circ} \mathrm{W}, N=11\right)$.

The samples were analyzed on a Hewlett-Packard 6890-5973 coupled GC/mass spectral detector (GC-MSD) with helium as the carrier gas. Two microliters of sample were injected in splitless mode and analyzed with both nonchiral phase (INNOWax; $60 \mathrm{~m} \times 0.25 \mathrm{~mm} \times$ $0.25 \mu \mathrm{m}$ film; Agilent Technologies, Wilmington, DE, USA) and chiral phase (GammaDex-225; $30 \mathrm{~m} \times 0.25 \mathrm{~mm} \times 0.25 \mu \mathrm{m}$ film; Supelco) capillary GC columns. For nonchiral GC-MS runs, the oven program was $40^{\circ} \mathrm{C}$ for $1 \mathrm{~min}, 16^{\circ} \mathrm{C} / \mathrm{min}$ to $80^{\circ} \mathrm{C}$, then $7^{\circ} \mathrm{C} / \mathrm{min}$ to $230^{\circ} \mathrm{C}$; for chiral runs, it was $40^{\circ} \mathrm{C}$ for $1 \mathrm{~min}, 5^{\circ} \mathrm{C} / \mathrm{min}$ to $70^{\circ} \mathrm{C}, 2^{\circ} \mathrm{C} / \mathrm{min}$ to $155^{\circ} \mathrm{C}$, then $25^{\circ} \mathrm{C} / \mathrm{min}$ to $220^{\circ} \mathrm{C}$, or alternatively, $40^{\circ} \mathrm{C}$ for $1 \mathrm{~min}$, then $5^{\circ} \mathrm{C} / \mathrm{min}$ to $220^{\circ} \mathrm{C}$. Analytes were quantified in the nonchiral runs by using response curves calculated from analyses of a dilution sequence of known quantities of compounds. Quantitative differences among treatment groups within sex were analyzed with a Kruskal-Wallis ANOVA followed by Dunn's test for pairwise comparisons ( $\alpha=0.05$; SPSS 1997).

Enantiomers of frontalin and endo-brevicomin in the samples were identified by retention time matches on the chiral column with synthetic standards of these enantiomers supplied by Phero Tech. We confirmed the optical rotation of the chiral endo-brevicomin standards by polarimetry. Enantiomeric ratios of frontalin and endo-brevicomin were calculated by examining single ion chromatograms of diagnostic ions for each compound (100 and $114 \mathrm{amu}$, respectively) and then computing the ratio of the integration areas of peaks at the confirmed retention times of the $(+)$ - and $(-)$-enantiomers. Response of the MSD had been found to be essentially linear through the range of enantiomer concentrations examined.

Attraction of $D$. frontalis to Synthetic Baits We evaluated the behavioral responses of $D$. frontalis to synthetic (+)-endo-brevicomin baits by using 12-unit multiple funnel traps erected within the same stand used for the artificially infested tree experiment during a period when it was experiencing a declining outbreak of $D$. frontalis. Traps were located $>100 \mathrm{~m}$ apart, $>10 \mathrm{~m}$ from the nearest susceptible pine, and $>1 \mathrm{~km}$ from the nearest known multiple-tree $D$. frontalis infestation. They were suspended from metal poles with the bottom funnel $\sim 1 \mathrm{~m}$ above the ground. Bait bioassay 1 (12 replicates; 18 September-17 October 2005) compared four bait treatments: pine turpentine; turpentine and $(+)$-endobrevicomin; turpentine and racemic frontalin; $(+)$-endo-brevicomin, racemic frontalin, and turpentine. Bait bioassay 2 (nine replicates; 17 January-1 March 2006) compared five bait treatments: unbaited trap; racemic frontalin; $(+)$-endo-brevicomin; racemic frontalin and $(+)$-endo-brevicomin; $(+)$-endo-brevicomin, racemic frontalin, and turpentine.

The frontalin bait consisted of two, 400- $\mu$ l-capacity LDPE microcentrifuge tubes containing racemic frontalin ( $>95 \%$ purity, Chemtica International). Turpentine (steam distilled from loblolly pine; Hercules Inc., Brunswick, GA, USA) was released from a 250$\mathrm{ml}$-capacity brown glass bottle with a piece of $1 \mathrm{~cm}$ diameter cotton dental wick immersed in the turpentine and protruding $2.5 \mathrm{~cm}$ through the cap. The (+)-endo-brevicomin was synthesized by the combination of procedures reported by Mori and Seu (1985) and Mori 
and Kiyota (1992) that employs lipase-catalyzed desymmetrization of a diol and Wacker oxidation of an olefin and was $>99 \%$ enantiomerically and $>95 \%$ chemically pure. It was released from a 1.17- $\mathrm{mm}$ i.d. glass capillary sealed at one end and suspended open-end up inside an inverted 2-ml glass vial. The frontalin and endo-brevicomin baits were suspended at the fourth funnel from the bottom of the trap, whereas the turpentine bottle was placed within the funnel immediately below the trap top (to protect the exposed wick from rain). Release rates were measured for all baits within a fume hood at $23 \pm 2^{\circ} \mathrm{C}$, either gravimetrically (turpentine, $7 \mathrm{~g}$ /day; frontalin, $5 \mathrm{mg} /$ day) or by loss of volume in the capillary (endo-brevicomin, $0.2 \mu \mathrm{l} / \mathrm{day}=0.2 \mathrm{mg} / \mathrm{day}$ ). Trap cups were filled with a few centimeters of propylene glycol and water, and catch was collected every 1-2 weeks. Traps were arranged into three lines with one trap per treatment and $150 \pm 50 \mathrm{~m}$ between traps. Treatments were assigned at random within lines and rerandomized without replacement to any previous position each time catch was collected. Each rerandomization/collection per trap line was one complete statistical block (=replicate). Raw catches of male and female $D$. frontalis were transformed with $\log (X+0.5)$ and analyzed for significant differences among treatment means by using a two-way ANOVA (factors were treatment and block) and Tukey's pairwise comparisons $(\alpha=0.05$; SPSS 1997). For bait treatments that trapped more than one insect, the proportion of males trapped per replicate was transformed $(\arcsin \sqrt{x})$, and treatments were compared with Student's $t$ test.

\section{Results}

Attraction of $D$. frontalis to Artificially Infested Trees In the first 2 days after introduction of males, trees caged with both sexes of $D$. frontalis attracted significantly greater numbers of conspecifics than trees caged with females alone (Fig. 2). This difference disappeared during the next 2 days. Beetle catch summed for all 4 days after introduction of males was likewise significantly higher for trees infested with both sexes (paired $t$ test; $P<0.001$ ). For this same period, sex ratio $(\mathrm{M} / \mathrm{F})$ of beetles trapped at trees with both sexes $(1.2: 1)$, and females only (1.6:1) did not differ significantly $(t$ test; $P=0.82)$. Dissections of the caged portions of trees revealed that both treatments had similar numbers of attacks initiated into

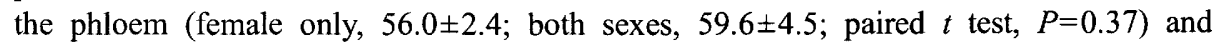

Fig. 2 Mean catches $( \pm \mathrm{SE})$ of $D$. frontalis in traps affixed to live pines artificially infested either with conspecific females or with both sexes. Catch was significantly different between treatments on days $2-3$ but not day 1 or days 4-5 (Paired $t$ test, $P<0.017)$

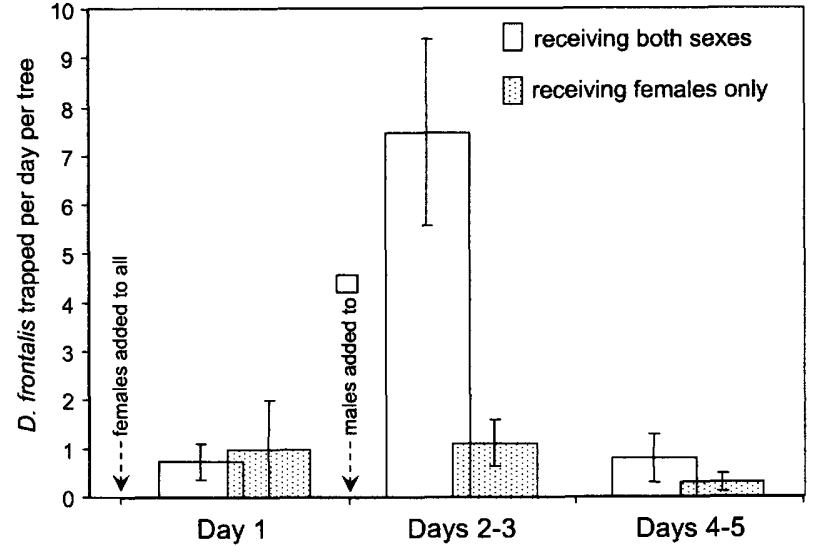




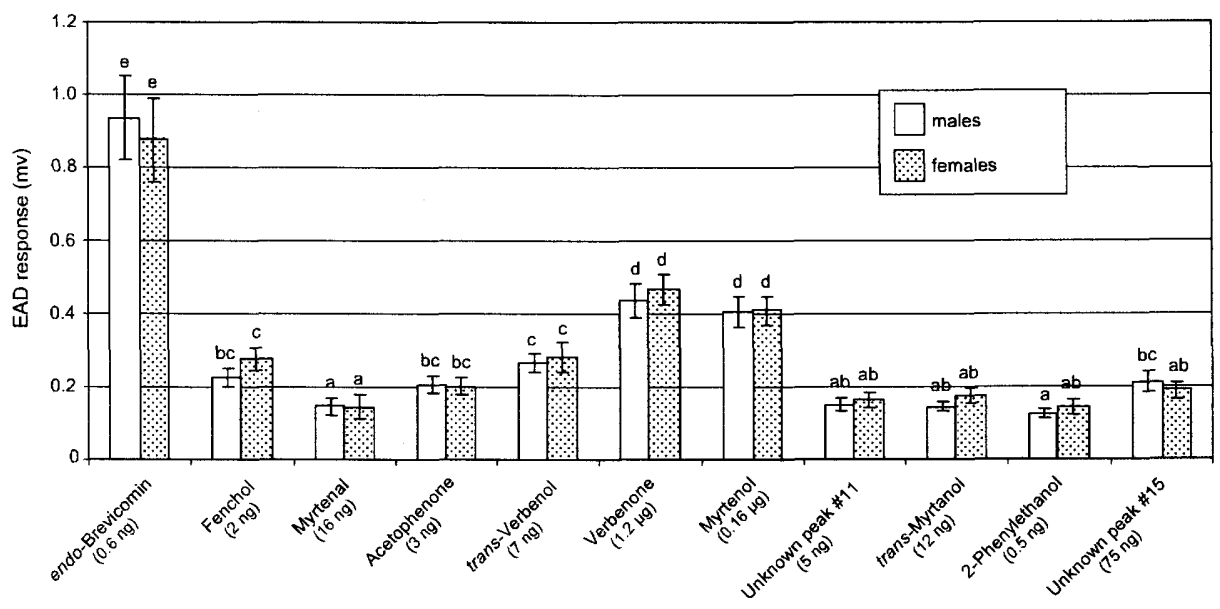

Fig. 3 Mean ( \pm SE) EAD response by antennae of $D$. frontalis exposed to 0.1 insect equivalents of pooled gut extract of 100 newly emerged male $D$. frontalis (Sullivan 2005). Within sex, means associated with the same letter were not significantly different $(\alpha=0.05$, Tukey test). The approximate quantity of each compound exposed to the antenna is given in parentheses

confirmed that, in trees that had received both sexes, a substantial number of males had

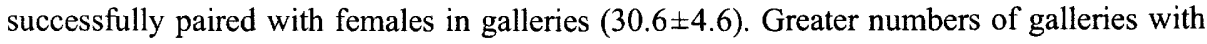
live, solitary females were found in female-only trees $(18.4 \pm 2.6)$ compared to trees receiving both sexes $(5.3 \pm 1.5$; paired $t$ test $P=0.005)$. Live, solitary females had mined in the phloem an average of $3.73 \pm 0.16 \mathrm{~cm}$, whereas live pairs had mined $7.81 \pm 0.22 \mathrm{~cm}$ (nonparametric $t$ test, $P<0.001$ ).

Electrophysiological Analyses In GC-EAD analyses of 0.1 insect equivalents of extract from newly emerged $D$. frontalis males, antennae of both sexes responded with

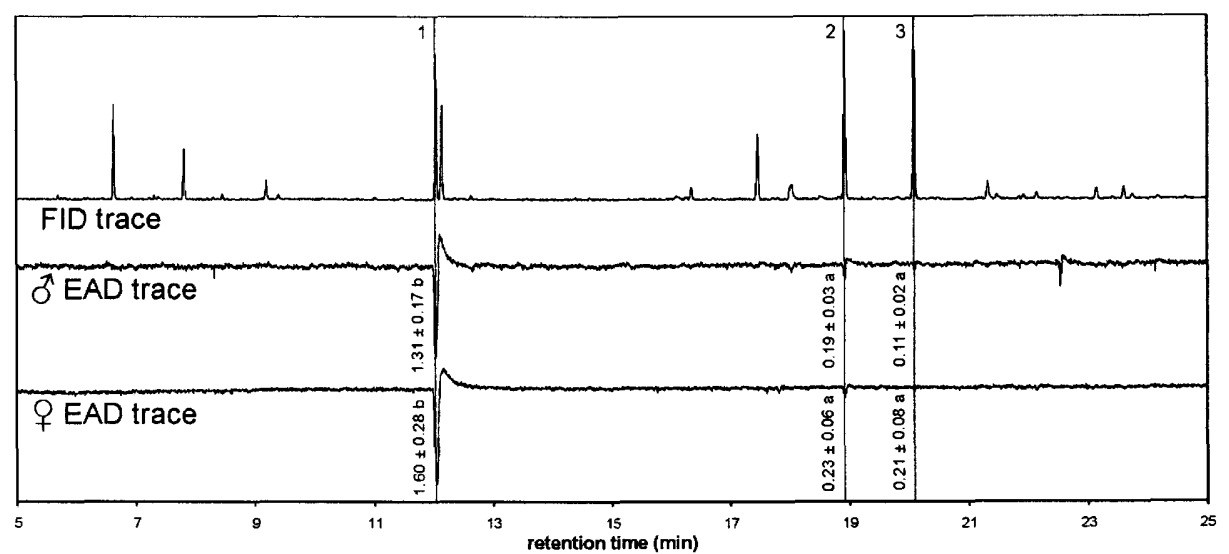

Fig. 4 GC-EAD traces of individual $D$. frontalis exposed to 0.1 insect equivalents of the pooled aerations/ extracts of 15 male $D$. frontalis that had been paired in a pine bolt with a female beetle for approximately 1 day. Peaks detected by the flame ionization detector $(F I D)$ that consistently coincided with an EAD deflection from either sex are numbered: endo-brevicomin, 1 ; verbenone, 2 ; myrtenol, 3 . Values adjacent to each EAD peak represent the mean $( \pm \mathrm{SE} \mathrm{mv})$ response of ten sampled antennae. Within sex, means associated with the same letter were not significantly different (Tukey test; $\alpha=0.05$ ) 
Fig. 5 Dose-response curves of EAD responses of female (a) and male (b) D. frontalis to the enantiomers of frontalin and endo-brevicomin resolved on a gamma-cyclodextrin-phase capillary column. Data points (mean response \pm SE) are shown only for concentrations for which the antennae registered a response that was significantly above the level of background noise (see text); hence, the furthest leftward point of each plot represents the response threshold for the enantiomer. The lowest concentration tested was $0.06 \mathrm{ng} / 1$
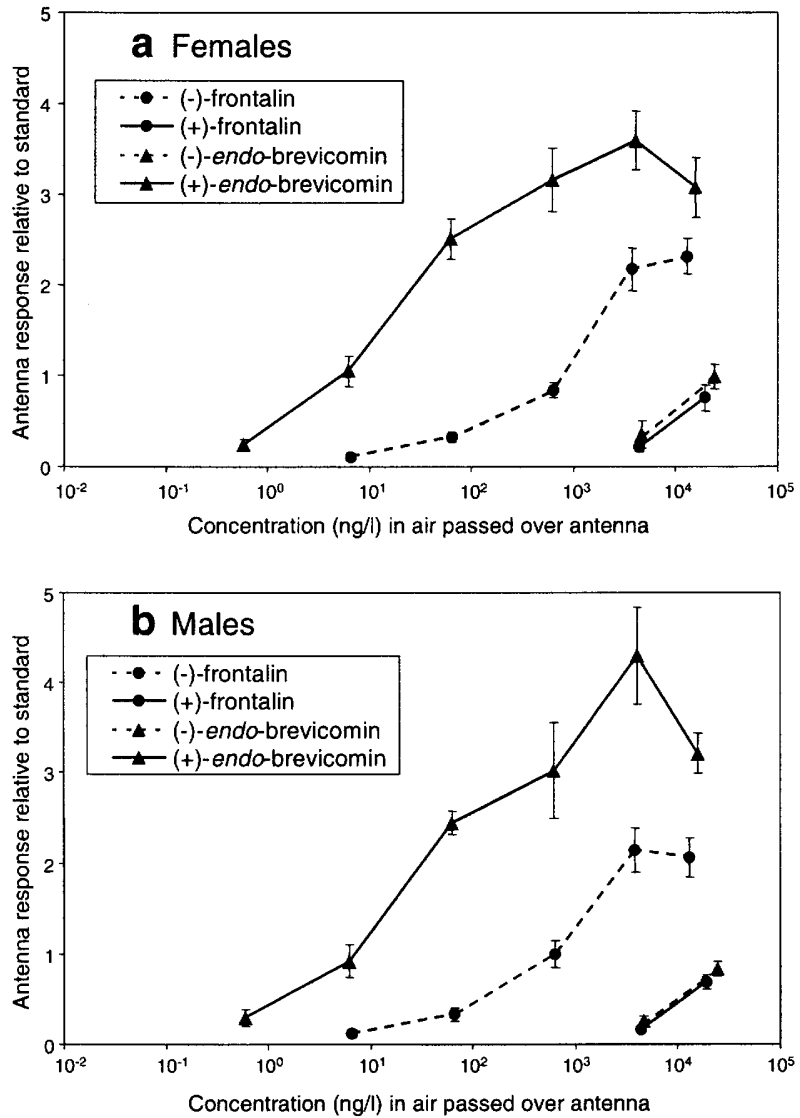

significantly higher voltages to endo-brevicomin than any other olfactory stimulant (Fig. 3). We found no olfactory stimulants in volatiles sampled from feeding, paired males that were not also produced by newly emerged individuals. When 0.1 insect equivalents of pooled volatiles from paired, mining males were analyzed by GC-EAD, only three compounds produced consistent responses from the antennae: endo-brevicomin, verbenone, and myrtenol (Fig. 4). endo-Brevicomin elicited significantly greater voltages from the antennae than either of the other two olfactory stimulants from paired males.

Exposure of $D$. frontalis antennae by chiral GC-EAD to a logarithmic progression of doses of the enantiomers of frontalin and endo-brevicomin revealed that, for both sexes, the threshold of detection for $(+)$-endo-brevicomin was four orders of magnitude lower than for either $(-)$-endobrevicomin or $(+)$-frontalin and one order of magnitude lower than for (-)-frontalin (Fig. 5). The threshold of detection for ( - -frontalin was three orders of magnitude lower than for its antipode. Through the entire range of concentrations tested, the mean response voltage elicited in the antennae was apparently higher for (+)-endo-brevicomin than for either enantiomer of frontalin or for $(-)$-endo-brevicomin.

Pheromone Isolation and Analysis Significant quantities of frontalin were detected from females and endo-brevicomin from males, whether newly emerged, mining singly, or mining in pairs (Fig. 6a). With a threshold of detection of approximately $1 \mathrm{ng}$ per beetle, frontalin was detected in only six of 110 male beetles sampled. These six came from all 
three treatment categories, and with one exception ( $9.5 \mathrm{ng}$ from a male mining singly), the quantity detected was $<3 \mathrm{ng}$. Similarly, traces of endo-brevicomin (1-3 ng) were detected in only seven of 96 females sampled. In contrast, endo-brevicomin was detected in $90 \%$ of emergent males, $81 \%$ of solitary mining males, and $100 \%$ of paired males; frontalin was detected in $100 \%$ of sampled females.

The quantity of frontalin detected from females excised while mining in a pine bolt was significantly (ninefold) higher than from newly emerged females (Fig. 6a). Less frontalin was detected from paired, mining females than females mining singly; however, these paired females had been in the bolt 1 day longer than the solitary ones, hence the relative effects of pairing vs time spent mining could not be distinguished. Males that had paired with a female in a gallery produced higher quantities of endo-brevicomin than males that were either newly emerged (15-fold) or mining singly (fivefold), whereas males mining singly did not differ significantly from newly emerged beetles (Fig. 6a). Peak recorded production of frontalin by females (i.e., females mining solitary, $547 \pm 63 \mathrm{ng}$ per beetle) was nearly twice the peak production of endo-brevicomin by males (i.e., males mining paired, $291 \pm 55 \mathrm{ng}$ per beetle). In contrast to endo-brevicomin, production of both verbenone and myrtenol were higher in newly emerged males than in those that were mining in a bolt either alone or paired, and the presence of a female did not significantly alter the production of these monoterpenes by mining males (Fig. 6b).

Fig. 6 Mean quantities ( \pm SE) of volatiles isolated from individual D. frontalis: the bicyclic ketals frontalin and endo-brevicomin from females and males, respectively (a) and the monoterpenes verbenone and myrtenol from males (b). Beetles $(N=31-34)$ either (1) had emerged within the previous $24 \mathrm{~h}$ from portions of a naturally infested pine, (2) had been infested onto a fresh pine bolt 1 day earlier, or (3) had been paired with a mate in a pine bolt for 1 day. In treatment 3 , females had been allowed to initiate a nuptial chamber for 1 day before introduction of male beetles and thus had been in the bolt 2 days when sampled. Within sex/compound, bars associated with the same letter were not significantly different (Dunn's test, $\alpha=0.05$ )
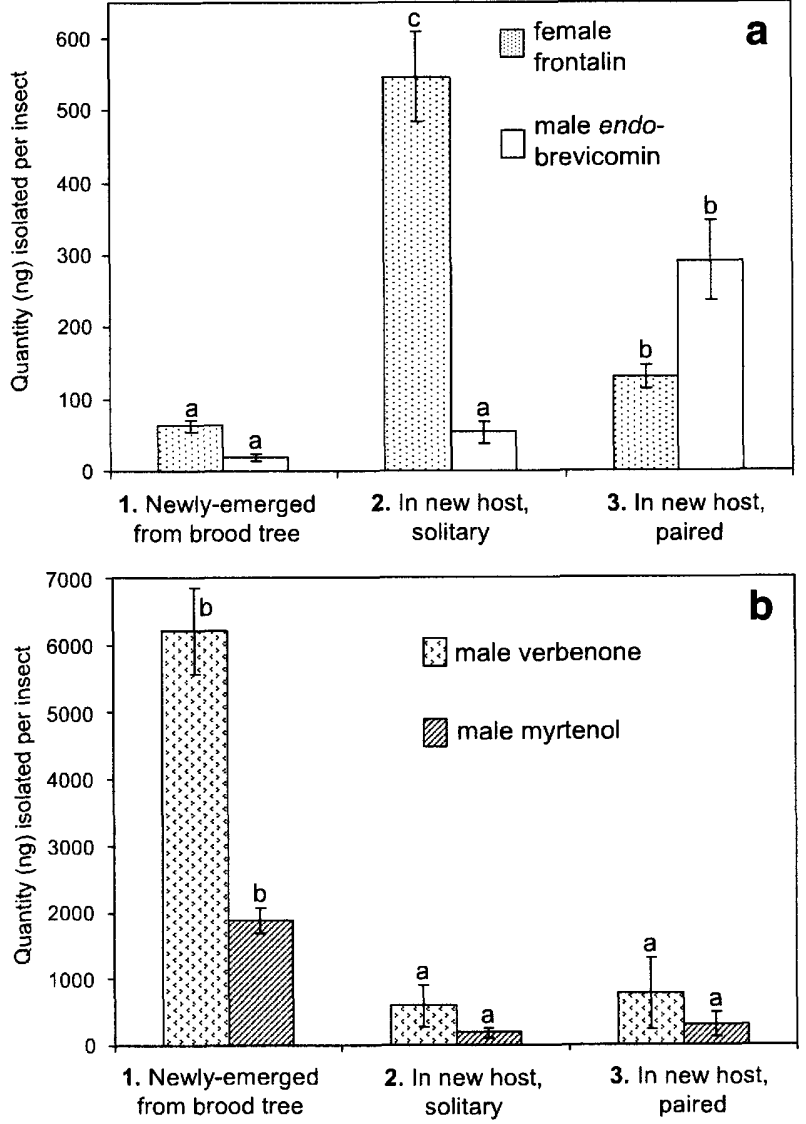

Q Springer 


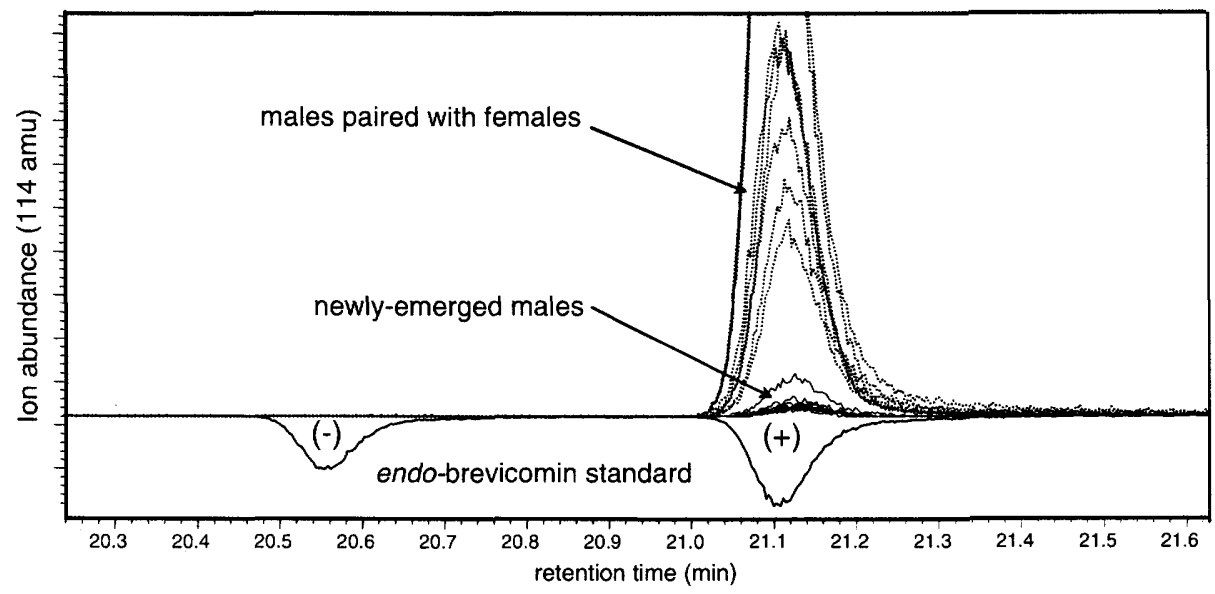

Fig. 7 Superimposed GC-MS single-ion chromatograms of volatiles from male $D$. frontalis resolved on an enantioselective GC column. Shown are eight traces each of aerations/extracts of either newly emerged males (positive traces, solid lines) or males paired with a female in a pine bolt $<1$ day (dotted lines), as well as a retention time standard containing a 1:2 ratio of $(-):(+)$ endo-brevicomin (inverted trace)

Only the (+)-enantiomer of endo-brevicomin was isolated from male beetles, irrespective of beetle treatment category or source population (Fig. 7). Because the amount of (-)-endobrevicomin never exceeded the MSD's threshold of detection in any sample, the mean enantiomeric ratio was not less than $86.5 \%(+): 13.5 \%(-) \pm 2.2 \%$ [i.e., the mean ratio of the quantity of $(+)$-endo-brevicomin to the threshold of detection observed in newly emerged males] for any treatment group or sampled population (Table 1). This lower limit of confidence is probably conservative given the fact that the ratio of $(+)$-endo-brevicomin to the threshold of detection exceeded 99:1 [i.e., $>99 \%(+)$-endo-brevicomin] in 18 samples. For female samples where both enantiomers of frontalin exceeded the threshold of detection ( 88 of 96 ), the mean enantiomeric ratio was $95.4 \%(-): 4.6 \%(+) \pm 0.7 \%$ SD. Feeding and/or pairing had no significant effect on the enantiomeric ratio of female frontalin (KruskalWallis ANOVA, $H=0.4843, d f=2, P=0.79$ ).

Attraction of D. frontalis to Synthetic Baits In bait bioassay 1 (Fig. 8), traps baited with turpentine, $(+)$-endo-brevicomin, and frontalin caught significantly more $D$. frontalis of either sex than turpentine either alone or paired with either frontalin or endo-brevicomin. Neither turpentine alone nor the combination of turpentine and (+)-endo-brevicomin attracted any $D$. frontalis, whereas turpentine combined with frontalin attracted greater numbers of males (and total beetles; $P=0.014$ ) than these treatments. Addition of $(+)$-endobrevicomin to frontalin/turpentine-baited traps resulted in a drop in the sex ratio of the responding beetles $(\mathrm{M} / \mathrm{F})$ from 3.4:1 to 1.3:1 $(P=0.032)$. In bait bioassay 2 (Fig. 9), traps baited with the combination of turpentine, $(+)$-endo-brevicomin, and frontalin caught significantly more $D$. frontalis of either sex than traps either lacking baits or baited with frontalin and/or (+)-endo-brevicomin in the absence of turpentine. Traps baited with $(+)$ endo-brevicomin alone failed to attract more beetles than nonbaited traps, whereas traps baited with frontalin alone attracted more females (and total beetles; $P=0.024$ ) than nonbaited traps. Traps baited with frontalin and $(+)$-endo-brevicomin did not differ significantly in catches from either nonbaited traps or traps baited with frontalin alone. The sex ratios $(\mathrm{M} / \mathrm{F})$ trapped by frontalin alone $(1.6: 1)$, frontalin/ $(+)$-endo-brevicomin $(1.1: 1)$, 
Table 1 Enantiomeric ratio of endo-brevicomin in volatiles collected from male $D$. frontalis as the minimum possible percentage of the $(+)$-enantiomer

\begin{tabular}{llll}
\hline Beetle Origin & \multicolumn{2}{l}{ Beetle Condition } & \\
\cline { 2 - 4 } & Newly Emerged & Mining Singly & Mining Paired \\
\hline $31.5^{\circ} \mathrm{N}, 89.0^{\circ} \mathrm{W}$ & $>86.5^{\mathrm{a}} \pm 2.2 \%^{\mathrm{b}}(27)^{\mathrm{c}}$ & $>92.3 \pm 1.9 \%(22)$ & $>98.6 \pm 0.4 \%(31)$ \\
$32.9^{\circ} \mathrm{N}, 87.1^{\circ} \mathrm{W}$ & $\mathrm{n} / \mathrm{a}$ & $\mathrm{n} / \mathrm{a}$ & $>98.7 \pm 0.2 \%(11)$ \\
$31.4^{\circ} \mathrm{N}, 91.1^{\circ} \mathrm{W}$ & $\mathrm{n} / \mathrm{a}$ & $\mathrm{n} / \mathrm{a}$ & $>98.6 \pm 0.2 \%(4)$ \\
\hline
\end{tabular}

${ }^{a}$ Mean ratio (as a percentage) of the abundance of the $(+)$-enantiomer to the threshold of detection of the MSD. Since (-)-endo-brevicomin was not detected, its greatest possible quantity in any sample was less than the threshold of detection.

${ }^{\mathrm{b}}$ Standard error of the mean

${ }^{\mathrm{c}}$ Sample size $(N)$

and frontalin/ $(+)$-endo-brevicomin/turpentine $(1.8: 1)$ did not significantly differ $(P>0.18)$; however, low numbers trapped by the turpentine-lacking treatments gave insufficient power to these comparisons.

\section{Discussion}

Our data provide the first direct evidence that $D$. frontalis males can enhance the aggregation of conspecifics to pines undergoing colonization (Fig. 2), implying that mass attack is mediated by pheromone components from both sexes. Thus $D$. frontalis resembles congeners D. adjunctus Blandford (Hughes et al. 1976), D. brevicomis LeConte (Wood and Bedard 1977), and D. ponderosae Hopkins (Borden et al. 1987) that have been shown to aggregate on pines in response to pheromone components from both sexes. However, two previous studies showed that pine bolts artificially infested with $D$. frontalis pairs were no more attractive to conspecifics than those infested solely with females (Coster et al. 1977; Svihra 1982). Whereas our girdling of experimental trees likely improved the chances of successful beetle attack and establishment (Tisdale et al. 2003), the defensive responses of these trees remained strong, as evidenced by pitch tubes at most beetle entrance holes and

Fig. 8 Bait bioassay 1: Mean (+SE) catch of D. frontalis in multiple-funnel traps baited with loblolly pine turpentine $(T),(+)-$ endo-brevicomin $(B)$, and/or racemic frontalin $(F)$. Within sex, bars associated with the same letter were not significantly different (Tukey test, $\alpha=0.05$ ). Total catch for each treatment/sex is given in parentheses

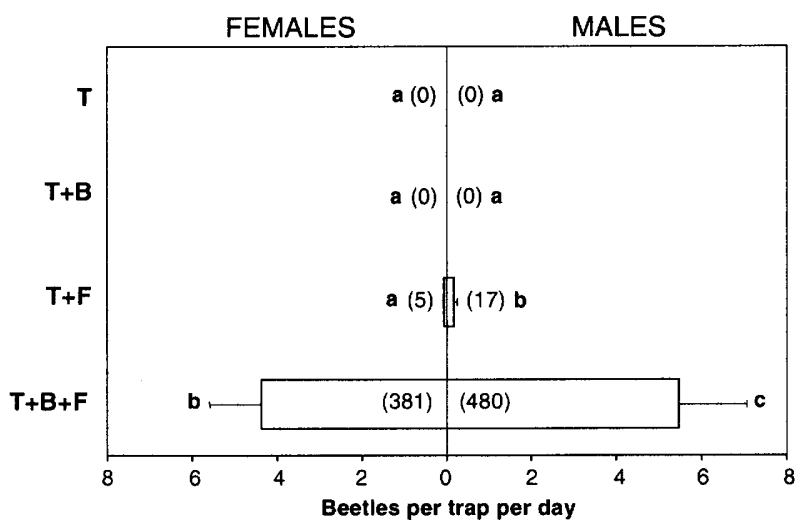


Fig. 9 Bait bioassay 2: Mean $(+\mathrm{SE})$ catch of $D$. frontalis in multiple-funnel traps baited with loblolly pine turpentine $(T),(+)$ endo-brevicomin $(B)$, and/or racemic frontalin $(F)$ or nothing (C). Within sex, bars associated with the same letter were not significantly different (Tukey test $\alpha=0.05$ ). Total catch for each treatment/sex is given in parentheses

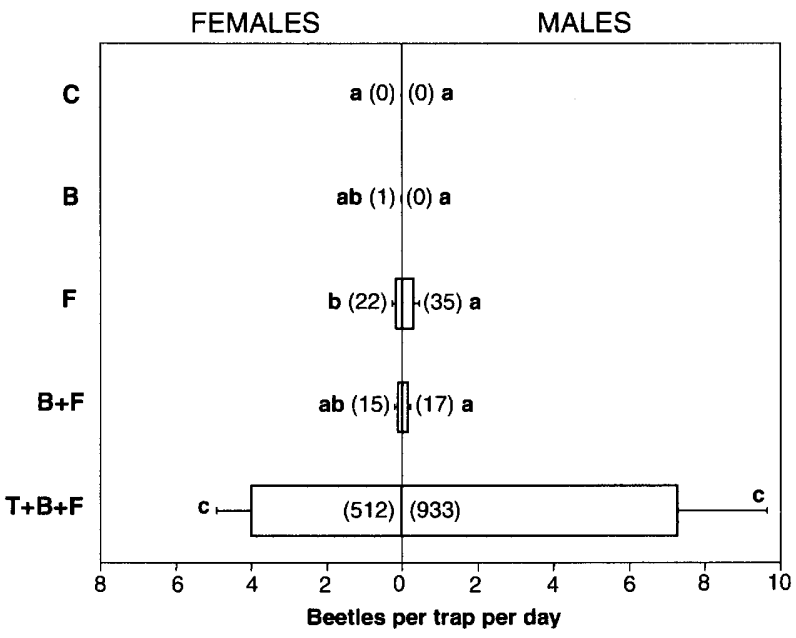

numerous beetles found "pitched" into their galleries. In contrast, pitch tubes rarely occur at entrances when beetles attack pine bolts (personal observation). Bolts cut from trees recently infested with $D$. frontalis rapidly lose attractiveness to conspecifics, and high host moisture content and resin exudation have been associated with enhanced aggregation by D. frontalis and other Dendroctonus spp. (Vité and Renwick 1968; Vité and Pitman, 1968). High resin production may delay beetle pairs from extending their galleries into the phloem and thus prolong pheromone release near the entrances. $D$. frontalis will sometimes attack and reproduce in dead or dying hosts, such as felled trees, that are presumably similar in quality to bolts (Moser et al. 1987); however, during outbreaks, they predominantly attack healthy trees. Hence, our infested-tree study may provide a more accurate picture of pheromone dynamics for outbreak-phase $D$. frontalis.

Bark beetles typically possess disproportionate olfactory sensitivity to components of their aggregation pheromones, which function over large distances and at low concentrations (Dickens 1979; Whitehead 1986; Smith et al. 1988). The exceptionally strong electrophysiological responses that $(+)$-endo-brevicomin elicited in the antennae of both sexes of $D$. frontalis singled-out this compound as a likely aggregation pheromone component (Figs. 3, 4, and 5). This result was also consistent with evidence that only the (+)-enantiomer of endo-brevicomin is attractive to D. frontalis (Vité et al. 1985). Dickens and Payne (1977) reported that among seven known semiochemicals for $D$. frontalis, endo-brevicomin ranked second only to frontalin in the percentage of olfactory acceptor sites occupied during odorant saturation.

Vité and Renwick (1971) reported that endo-brevicomin was produced merely in "subnanogram quantities by certain males" and therefore questioned whether this compound was a true pheromone for $D$. frontalis. Grosman et al. (1997) isolated an average of $17 \mathrm{ng}$ endo-brevicomin per male beetle from three geographically isolated $D$. frontalis populations. These earlier studies examined only newly emerged beetles (Pitman et al. 1969; Grosman et al. 1997), which according to our data, produce relatively small amounts of endo-brevicomin (Fig. 6a). In contrast, we isolated nearly $300 \mathrm{ng}$ endobrevicomin on average from paired males, an amount roughly comparable to the frontalin isolated from mining females.

Production of frontalin in females was stimulated by mining in the host, whereas endobrevicomin production in males was stimulated by pairing (Fig. 6a). In contrast, other maleproduced compounds such as verbenone and myrtenol declined in concentration once males 
entered the bark (Fig. 6b; Sullivan 2005). The majority of such compounds (including verbenone, myrtenol, fenchol, myrtenal, acetophenone, trans-myrtanol, and 2-phenylethanol) are attractant antagonists (Payne et al. 1978; Sullivan 2005; Sullivan et al. 2007), and the separation in the timing of their production relative to endo-brevicomin is consistent with differing behavioral functions. This finding also suggests that synthesis and/or accumulation of endo-brevicomin is regulated by physiological mechanisms different from other male-produced compounds. In support of this inference, treatment of 5-day-old, callow adult male $D$. frontalis with either juvenile hormone II or the juvenile hormone analog methoprene stimulated an increase in hindgut concentrations of endo-brevicomin but not verbenone or myrtenol (Bridges 1982). Independent regulation of endo-brevicomin is also implied by evidence that bark beetle-produced bicyclic ketals like brevicomin and frontalin are synthesized de novo, whereas oxygenated monoterpenes such as verbenone and myrtenol may be derived from ingested or inhaled host monoterpenes (Hughes 1973; Seybold and Tittiger 2003).

Vité et al. (1985) first hypothesized that the complete aggregation pheromone of $D$. frontalis included male-produced (+)-endo-brevicomin, which they found to cause a fivefold increase in attraction to female-produced frontalin and host terpenes. Our data confirm their results (Fig. 8) while documenting a remarkable 40-fold enhancement effect from the addition of $(+)$-endo-brevicomin to a frontalin/host terpene bait. However, Vité et al. (1985) also showed that (-)-endo-brevicomin is an attractant antagonist, and there are conflicting data on the enantiomeric ratios of endo-brevicomin produced by $D$. frontalis males. Redlich et al. (1987) found approximately $97 \%$ of the $(+)$-enantiomer when they used enantioselective capillary GC-MS to analyze aerations and hindgut extracts of emergent male $D$. frontalis. Grosman et al. (1997) used enantioselective GC-FID to analyze gut extracts from emergent males from three different populations and reported a range of $9-21 \%(+)$ with no significant variation among regions. In contrast, our examination of aerations/extracts of male $D$. frontalis using enantioselective GC-MS failed to detect even trace quantities of $(-)$-endo-brevicomin, despite detecting the $(+)$-enantiomer at hundreds of times the detection threshold of the MSD (Fig. 7).

The disparity among these three data sets was most likely caused by differences in the reliability of the analytical techniques, because no significant geographic variation in the enantiomeric ratio of endo-brevicomin was identified in our data or those of Grosman et al. (1997). Our findings and those of Redlich et al. (1987) both indicated that the (+)enantiomer was predominant, and both studies were performed by using MSD chromatograms of single, diagnostic ions for endo-brevicomin. This procedure would have largely ensured that only the target molecule was quantified and would have prevented overestimation of the abundance of (-)-endo-brevicomin because of coelution of compounds indistinguishable by FID alone, as could have occurred in the study of Grosman et al. (1997). Additionally, our study provided a more meaningful picture of endobrevicomin chirality than previous ones, because it examined paired males, apparently the only life stage that produces this compound in large quantities. The greater olfactory sensitivity of both sexes for (+)-endo-brevicomin and (-)-frontalin than for the respective antipodes (Fig. 5; Payne et al. 1982) mirrors the greater production of these enantiomers by the insects. Thus, the totality of evidence indicates that $D$. frontalis is utilizing only $(+)$ endo-brevicomin, the attractive enantiomer as shown by Vité et al. (1985).

Among Dendroctonus spp., a pheromone component produced predominantly by one sex typically elicits the strongest attractive response from the opposite sex (Vité and Pitman 1969; Hughes et al. 1976; Borden et al. 1987; Payne et al. 1987). In concurrence, Vité et al. 
(1985) observed that addition of male-produced (+)-endo-brevicomin to attractant-baited traps shifted the sex ratio $(\mathrm{M} / \mathrm{F})$ from $4.6: 1$ to $2.0: 1$. In our study, both the introduction of males to female-infested trees and the addition of $(+)$-endo-brevicomin to traps baited with frontalin either alone or with turpentine caused the male-biased sex ratio of attracted beetles to shift closer to a balance between the sexes. However, these sex ratio differences were statistically significant only in bait bioassay 1 , possibly because of the low catch of beetles by at least one of the treatments in these various pairwise comparisons. Our GC-EAD studies showed that the sexes differed little in their olfactory sensitivity for $(+)$-endobrevicomin (Fig. 5), indicating that any sexually dimorphic behavioral responses to (+)endo-brevicomin are not reflected in sex-specific abundance of olfactory receptors.

The dramatic increase in beetle attraction observed when $(+)$-endo-brevicomin was added to frontalin/turpentine suggests that this compound is an important component of the $D$. frontalis aggregation pheromone and that it is critical in mediating successful mass attacks on host trees. However, in contrast to frontalin, $(+)$-endo-brevicomin appeared to be entirely unattractive to $D$. frontalis in the absence of other compounds (Fig. 9) and showed no ability to act synergistically with turpentine (Fig. 8; Billings 1985). Hence, the male and female aggregation pheromone components do not play equivalent or reciprocal roles. Curiously, (+)-endo-brevicomin exhibited no synergistic activity with frontalin alone (Fig. 9), but the low catch by these treatments gave inadequate statistical power to their comparison. Dendroctonus males are not known to initiate attacks; hence, the failure of $D$. frontalis to respond to male pheromone components alone or with host odors seems consistent with females' exclusive role as pioneers. Nonetheless, attraction to maleproduced compounds in the absence of those from females has been documented in $D$. adjunctus (Hughes et al. 1976) and D. terebrans (Olivier; Payne et al. 1987; Phillips et al. 1990 ), and the male-produced compound frontalin can induce $D$. ponderosae to colonize baited pines (Borden et al. 1990).

Several earlier studies showed that $( \pm)$-endo-brevicomin can inhibit $D$. frontalis from responding to attractant-baited traps or landing on host trees (Vité and Renwick 1971; Payne et al. 1978; Richerson and Payne 1979; Salom et al. 1992). These findings prompted the conclusion that endo-brevicomin functioned as an antiaggregation pheromone for this species (Payne 1980; Skillen et al. 1997). However, after their discovery of the opposing activities of the enantiomers of endo-brevicomin, Vité et al. (1985) theorized that the inhibitory activity of the racemate was because of the antagonistic activity of the (-)enantiomer overriding the attractive activity of the (+)-enantiomer.

We propose that male $D$. frontalis accelerate the aggregation of conspecifics to trees undergoing attack by releasing $(+)$-endo-brevicomin that acts synergistically with frontalin from females and host resin terpenes. The potential fitness benefits to pheromoneproducing males are enhanced survival for both themselves and their offspring, as attracting greater numbers of attacking conspecifics should help assure rapid and complete disruption of host defenses. Alternately, males and females responding to hosts releasing $(+)$-endobrevicomin, frontalin, and host terpenes (hosts infested with at least some beetle pairs) may avoid the high risks of mortality encountered by pioneer beetles that are first to initiate attacks on a particular tree (Pureswaran et al. 2006). Our data also indicate that the attractant currently used for monitoring populations of $D$. frontalis with traps (frontalin and turpentine; Skillen et al. 1997) is incomplete and that the addition of (+)-endo-brevicomin may enhance detection of low-density beetle populations. Additionally, this novel, enhanced-potency bait may prove efficacious in trap-out and other attractant-based management strategies for $D$. frontalis. 
Acknowledgments We thank Brad Hoosier, Erich Vallery, Tessa Bauman, Chris Young, Jolie Mahfouz, James McDonald, and Alicia Niño for technical assistance; Drs. K. Fuhshuku and Y. Masuda of RIKEN, Japan, for help with the synthesis of (+)-endo-brevicomin; Mark Dalusky for providing us with $D$. frontalis from Alabama; Lee Dunnam, Homochitto National Forest, Mississippi, for assistance and cooperation in field studies; Larry Roton for useful insights that greatly influenced our thinking on this topic; Rhonda Tam and Jessica Norris for administrative assistance; Steve Clarke, Jim Meeker, and John Reeve for critical readings of earlier versions of this manuscript; and John Borden for extensive editing of the final text.

\section{References}

Bhattacharyya, G. K., and Johnson, R. A. 1977. Statistical Concepts and Methods. Wiley, New York.

BILLINGS, R. F. 1985. Southern pine bark beetles and associated insects: effects of rapidly-released host volatiles on response to aggregation pheromones. J. Appl. Entomol. 99:483-491.

Borden, J. H., RyKer, L. C., ChONG, L. J., Pierce, H. D. JR., Johnston, B. D., and Oehlschlager, A. C. 1987. Response of the mountain pine beetle, Dendroctonus ponderosae Hopkins (Coleoptera: Scolytidae), to five semiochemicals in British Columbia lodgepole pine forests. Can. J. For. Res. 17:118-128.

BORDEN, J. H., ChONG, L. J., and LINDGREN, B. S. 1990. Redundancy in the semiochemical message required to induce attack on lodgepole pines by the mountain pine beetle Dendroctonus ponderosae Hopkins (Coleoptera: Scolytidae). Can. Entomol. 122:769-777.

BRIDGES, J. R. 1982. Effects of juvenile hormone on pheromone synthesis in Dendroctonus frontalis. Environ. Entomol. 11:417-420.

BROWNE, L. E. 1972. An emergence cage and refrigerated collector for wood-boring insects and their associates. J. Econ. Entomol. 65:1499-1501.

COSTER, J. E., and VITÉ, J. P. 1965. Effects of feeding and mating on pheromone release in the southern pine beetle. Ann. Entomol. Soc. Am. 65:263-266.

Coster, J. E., PAYNe, T. L., HART, E. R., and EDson, L. J. 1977. Aggregation of the southern pine beetle in response to attractive host trees. Environ. Entomol. 6:725-731.

DICKENS, J. C. 1979. Electrophysiological investigations of olfaction in bark beetles. Bull. Soc. Entomol. Suisse 52:203-216.

DICKENS, J. C., and PAYNE, T. L. 1977. Bark beetle olfaction: pheromone receptor system in Dendroctonus frontalis. J. Insect Physiol. 23:481-489.

Grosman, D. M., Salom, S. M., Ravlin, F. W., and Young, R. W. 1997. Geographic and gender differences in semiochemicals in emerging adult southern pine beetle (Coleoptera: Scolytidae). Ann. Entomol. Soc. Am. 90:438-446.

HUGHES, P. R. 1973. Dendroctonus: production of pheromones and related compounds in response to host monoterpenes. Z. Angew. Enomol. 73:294-312.

Hughes, P. R., RENwiCK, J. A. A., and Vité, J. P. 1976. The identification and field bioassay of chemical attractants in the roundheaded pine beetle. Environ. Entomol. 5:1165-1168.

MORI, K., and KIYOTA, H. 1992. A new synthesis of (3S,4R)-8-nonene-3,4-diol, the key intermediate for the synthesis of (+)-endo-brevicomin. Liebigs Ann. Chem. 989-992.

MORI, K., and SEU, Y. B. 1985. Synthesis of both the enantiomers of endo-brevicomin, the aggregation pheromone of Dryocoetes autographus. Tetrahedron 41:3429-3431.

Moser, J. C., SOMmers, R. A., LORIO, P. L. JR., BRIDGES, J. R., and WITCOSKY, J. J. 1987. Southern pine beetles attack felled green timber. USDA Forest Service Research Note SO-342. U.S. Department of Agriculture, Forest Service, Southern Forest Experiment Station, New Orleans, LA.

PAYNE, T. L. 1980. Life history and habits. pp. 31-54, in R. C. Thatcher, J. L. Searcy, J. E. Coster, and G. D. Hertel (eds.). The Southern Pine Beetle, U.S.D.A. Forest Service Science and Education Administration Technical Bulletin 1631. U.S. Department of Agriculture, Forest Service, Southern Forest Experiment Station, New Orleans, LA

PAYNE, T. L., and RICHERSON, J. V. 1979. Management implications of inhibitors for Dendroctonus frontalis (Col. Scolytidae). Bull. Soc. Entomol. Suisse 52:323-331.

PAYNE, T. L., COSTER, J. E., and JOHNSON, P. C. 1977. Effects of slow-release formulation of synthetic endoand exo-brevicomin on southern pine beetle flight and landing behavior. J. Chem. Ecol. 3:133-141.

PAYNe, T. L., Coster, J. E., Richerson, J. V., EDSON, L. J., and HART, E. R. 1978. Field response of the southern pine beetle to behavioral chemicals. Environ. Entomol. 7:578-582. 
Payne, T. L., Richerson, J. V., Dickens, J. C., West J. R., Mori, K., Berisford, C. W., Hedden, R. L., VITÉ, J. P., and BLUM, M. S. 1982. Southern pine beetle: olfactory receptor and behavior discrimination of enantiomers of the attractant pheromone frontalin. J. Chem. Ecol. 8:873-881.

Payne, T. L., Billings, R. F., Delorme, J. D., Andryszak, N. A., Bartels, J., Francke, W., and Vité, J. P. 1987. Kairomonal-pheromonal system in the black turpentine beetle, Dendroctonus terebrans (Ol.). $J$. Appl. Entomol.103:15-22.

Payne, T. L., Billings, R. F., Berisford, C. W., SAlom, S. M., Grosman, D. M., Dalusky, M. J., and Upron, W. W. 1992. Disruption of Dendroctonus frontalis (Col. Scolytidae) infestations with an inhibitor pheromone. J. Appl. Entomol. 114:341-347.

Phillips, T. W., Nation, J. L., Wilkinson, R. C., Foltz, J. L., Pierce, H. D. JR., and Oehlschlager, A. C. 1990. Response specificity of Dendroctonus terebrans (Coleoptera: Scolytidae) to enantiomers of its sex pheromones. Ann. Entomol. Soc. Am. 83:251-257.

Pitman, G. B., Vité, J. P., Kinzer, G. W., and Fentiman, A. F. JR. 1969. Specificity of populationaggregating pheromones in Dendroctonus. J. Insect Physiol. 15:363-366.

Pureswaran, D. S., SUllivan, B. T., and AYres, M. P. 2006. Fitness consequences of pheromone production and host selection strategies in a tree-killing bark beetle (Coleoptera: Curculionidae: Scolytinae). Oecologia 148:720-728.

Redlich, H., BRuns, W., FrancKe, W., Schurig, V., PAyne, T. L., and Vité, J. P. 1987. Chiral building units from carbohydrates. XIII. Identification of the absolute configuration of endo-brevicomin from Dendroctonus frontalis and synthesis of both enantiomers from D-ribose. Tetrahedron 43:2029-2034.

RENWICK, J. A. A., and VITÉ, J. P. 1969. Bark beetle attractants: mechanism of colonization by Dendroctonus frontalis. Nature 224:1222-1223.

RENWICK, J. A. A., and VITÉ, J. P. 1970. Systems of chemical communication in Dendroctonus. Contrib. Boyce Thompson Inst. 24:283-292.

RICHERSON, J. V., and PAYNE, T. L. 1979. Effects of bark beetle inhibitors on landing and attack behavior of the southern pine beetle associates. Environ. Entomol. 8:360-364.

Salom, S. M., Billings, R. F., Upton, W. W., Dalusky, M. J., Grosman, D. M., Payne, T. L., BERISFORD, C. W., and SHAVER, T. N. 1992. Effect of verbenone enantiomers and racemic endobrevicomin on response of Dendroctonus frontalis (Coleoptera: Scolytidae) to attractant-baited traps. Can. J. For. Res. 22:925-931.

SEYBOLD, S. J., and TITTIGER, C. 2003. Biochemistry and molecular biology of de novo ispoprenoid pheromone production in the Scolytidae. Annu. Rev. Entomol. 48:425-53.

Skillen, E. L., Berisford, C. W., CAmaAn, M. A., and REARDON, R. C. 1997. Semiochemicals of forest and shade tree insects in North America and management applications. USDA Forest Service Forest Health Technology Enterprise Team Publication FHTET-96-15. U.S. Department of Agriculture, Forest Service, Southern Forest Experiment Station, New Orleans, LA

SMith, M. T., BusCh, G. R., PAYNE, T. L., and DiCKENS, J. C. 1988. Antennal olfactory responsiveness of three sympatric Ips species [Ips avulsus (Eichhoff), Ips calligraphus (Germar), Ips grandicollis (Eichhoff)], to intra- and interspecific behavioral chemicals. J. Chem. Ecol. 14:1289-1304.

SMITH, M. T., SALOM, S. M., and PAYNE, T. L. 1993. The southern pine bark beetle guild: a historical review of the research on the semiochemical-based communication system of the five principal species. Virginia Agricultural Experiment Station Bulletin 93-4. Virginia Agricultural Experiment Station, Blacksburg, VA.

SPSS. 1997. SigmaStat ${ }^{\circledR 2} 2.0$ for Windows ${ }^{\circledR}$ User's Manual. SPSS Inc., Chicago, IL.

SULLIVAN, B. T. 2005. Electrophysiological and behavioral responses of Dendroctonus frontalis (Coleoptera: Curculionidae) to volatiles isolated from conspecifics. J. Econ. Entomol. 98:2067-2078.

Sullivan, B. T., Dalusky, M. J., WaKARChuK, D., and Berisford, C. W. 2007. Field evaluations of potential aggregation inhibitors for the southern pine beetle, Dendroctonus frontalis (Coleoptera: Curculionidae). J. Entomol. Sci. 42:139-149.

SVIHRA, P. 1982. Influence of opposite sex on attraction produced by pioneer sex of four bark beetles species cohabiting pine in the southern United States. J. Chem. Ecol. 8:373-378.

TiSDAle, R. A., NEBEKer, T. E., and Hodges, J. D. 2003. Role of oleoresin flow in initial colonization of loblolly pine by southern pine beetle. J. Entol. Sci. 38:576-582.

VITÉ, J. P., and PITMAN, G. B. 1968. Bark beetle aggregation: effects of feeding on the release of pheromones in Dendroctonus and Ips. Nature 218:169-170.

VITÉ, J. P., and RENWICK, J. A. A. 1968. Insect and host factors in the aggregation of the southern pine beetle. Contrib. Boyce Thompson Inst. 24:61-63.

Vité, J. P., and Pitman, G. B. 1969. Aggregation behavior of Dendrocotnus brevicomis in response to synthetic pheromones. J. Insect Phyiol. 15:1617-1622. 
VITÉ, J. P., and RENwICK, J. A. A. 1971. Inhibition of Dendroctonus frontalis response to frontalin by isomers of brevicomin. Naturwissenschaften 8:418-419.

VITÉ, J. P., and FRANCKE, W. 1976. The aggregation pheromones of bark beetles: Progress and problems. Naturwissenschaften 63:550-555.

Vité, J. P., BILlingS, R. F., WARE, C. W., and MORI, K. 1985. Southern pine beetle: enhancement or inhibition of aggregation response mediated by enantiomers of endo-brevicomin. Naturwissenschaften 72:99.

WHITEHEAD, A. T. 1986. Electroantennogram responses by mountain pine beetles, Dendroctonus ponderosae Hopkins, exposed to selected semiochemicals. J. Chem. Ecol. 12:1603-1621.

WOOD, D. L., and BEDARD, W. D. 1977. The role of pheromones in the population dynamics of the western pine beetle. Proc. Int. Congr. Entomol. 15:643-652.

WOOD, S. L. 1982. The bark and ambrosia beetles of North and Central America (Coleoptera: Scolytidae), a taxonomic monograph. Gt. Basin Nat. Mem. 6:1359. 